\title{
TEM Analysis of an Actinide-Bearing Sorbent: Monosodium Titanate
}

\author{
N. L. Dietz*, M. C. Duff**, D. T. Hobbs** \\ *Argonne National Laboratory, Chemical Technology Division, Argonne, IL 60439 \\ **Westinghouse Savannah River Company, Savannah River Site, Aiken, SC 29808
}

Designs for the treatment of High-Level Radioactive Waste (HLW) at the Savannah River Site include the possible use of monosodium titanate (MST) for the removal of selected actinides. Titanates have a strong affinity for dissolved actinides under conditions relevant to processing of highly alkaline HLW salt solutions, but the mechanism of uptake by MST is unknown. Transmission Electron Microscopy (TEM) analyses was done to determine MST microstructure and actinide distribution on uranium(VI)-doped and plutonium-doped monosodium titanate powders that were prepared using HLW simulant salt solutions. A Pu(IV)-doped MST and a $\mathrm{Pu}(\mathrm{VI})$-doped MST sample were compared. This study attempted to gain complementary information to previous XAFS analyses on these materials [1,2].

Samples were prepared by ultramicrotomy using a Reichart Ultracut E Ultramicrotome. The analyses were done with a $200 \mathrm{keV}$ JEOL 2000FX TEM.

The MST particles consist of an amorphous or nanocrystalline interior surrounded by highly distorted sheets of crystalline "fringes". The outer-fringed layer has a sheet-like structure and varies in thickness from approximately $200-500 \mathrm{~nm}$. Diffraction analyses indicate that the composition of the fringe material is unique and does not resemble that of known titanate structures. The outer fringed portion of the MST has a highly distorted lattice structure, indicating some lack of order in the crystal structure. This distortion could be due to interstitial water, hydroxide $\left(\mathrm{OH}^{-}\right)$or from the presence of distorted Ti octahedra. The existence of highly distorted Ti octahedra in MST agrees with previous XAFS work that determined sorption of actinides is site specific and probably occurs on distorted and perfect Ti octahedra on the MST.

Figure 1A shows a cross-section through an intact $\mathrm{Pu}(\mathrm{IV})$-doped MST particle. This image is representative of the MST morphology in each analyzed sample. Figure 1B shows a lattice plane image of the fringe layer. A lattice spacing of $0.63 \mathrm{~nm}$ was measured from the image. Given that $\mathrm{Pu}$ was present at $553 \mathrm{mg} / \mathrm{kg}(0.05 \mathrm{wt} . \%)$ in this sample, it was not detectable using EDS or EELS. To verify that the thin sections contained $\mathrm{Pu}$, the grid was analyzed with alpha spectrometry to measure the total amount of $\mathrm{Pu}$ in all the thin sections the grid. The total $\mathrm{Pu}$ mass on the grid was $9.58 \times 10^{-7} \mu \mathrm{g}$. Each grid contained 15- to $2050-\mathrm{nm}$ thick sections, with dozens of MST particles within each section. These results indicate that $\mathrm{Pu}$ is highly dispersed in the sample in that $\mathrm{Pu}$ was not detected by EELS or observed as colloids in the MST microstructure. In comparison to the other samples, no substantial morphological differences existed in MST reacted with $\mathrm{Pu}(\mathrm{IV})-, \mathrm{Pu}(\mathrm{VI})$-, or U(VI)-containing solutions. However, the Udoped MST sample had an average lattice fringe spacing of $0.62 \mathrm{~nm}$ with a larger range of lattice spacing (0.55 to $0.67 \mathrm{~nm}$ ) than the Pu-doped MST particle. Although EDS and EELS did not detect $\mathrm{Pu}$ or $\mathrm{U}$ from these samples, this does not rule out the possibility that $\mathrm{Pu}$ is present as small $\mathrm{Pu}$ oxide colloids as previously observed by XAFS because the analyzed portion of a thin section of material may not have contained the Pu colloids. 
The combined results of this study, previous XAFS [1,2] and TEM of Sr-doped MST [3] indicate that an improvement to MST sorbent design could include the synthesis of particles with a higher fringe-to-amorphous component ratio. In addition, additional TEM analysis with higher actinide loading is recommended.

\section{References}

[1] M.C. Duff, et al., Characterization of Sorbed Uranium, Plutonium and Neptunium on Monosodium Titanate. Westinghouse Savannah River Company report, WSRC-TR-200100356, Sept. 19, 2001.

[2] M.C. Duff, et al., Characterization of Sorbed Strontium on Monosodium Titanate. Westinghouse Savannah River Company report, WSRC-TR-2001-0245, June 25, 2001. [3] N.L. Dietz, et al., Transmission Electron Microscopy Analyses of Strontium and ActinideBearing Monosodium Titanate and Permanganate Treatment Solids, Westinghouse Savannah River Company report, WSRC-TR-2002-00363, Revision 0, Sept. 19, 2002.

[4] This study was performed in connection with work done under Contract Number DE-AC0996SR18500 for the U.S Department of Energy.
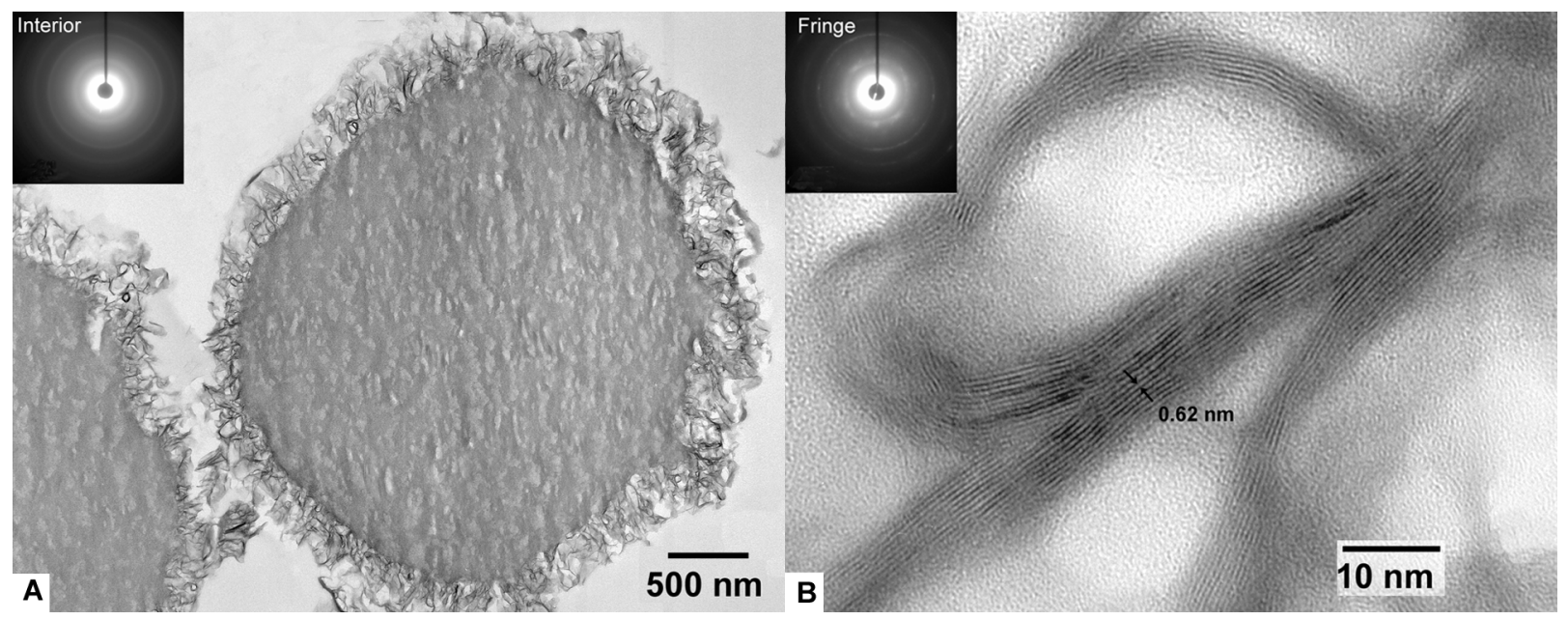

Figure 1. A) Cross section through Pu-doped MST particles. SAED pattern (insert) shows amorphous or nanocrystalline particle interior structure. B) Lattice fringe image of the outer fringes. SAED pattern shows nanocrystalline distorted fringe structure. 